\title{
7. HEALTH BEHAVIOURS
}

Health behaviours represent an important range of factors that influence child health and wellbeing, from the antenatal period and beyond. Parental health behaviours - such as maternal smoking and diet-can directly influence children in the early years. Along with the school and social environments, parenting styles, parental messages, early childcare, and education in early childhood, all have an influence on child health behaviours as children grow up. Health behaviours in childhood affect health in later life, because behaviours in childhood influence behaviours in adulthood, and because the beginnings of many chronic diseases actually occur in childhood.

\section{Smoking in pregnancy}

Smoking in pregnancy is one of the most important risk factors associated with adverse perinatal outcomes. It is associated with complications such as placenta previa and abruptio placentae, spontaneous abortion, premature rupture of the membranes, pre-term birth, low birthweight, and sudden infant death syndrome (SIDS). ${ }^{1}$ Additionally, it increases the risk for the later development of childhood allergies and asthma. ${ }^{2}$

In the New South Wales Child Health Survey 2001, mothers of babies aged less than 12 months were asked about their smoking behaviour during pregnancy. One in seven mothers (14.2 per cent) reported any smoking during pregnancy, with 7.9 per cent of mothers continuing to smoke but reducing their smoking, 3.6 per cent successfully quitting, 2.1 per cent unsuccessfully trying to quit, and 0.6 per cent continuing their previous smoking behaviour during pregnancy. The remaining mothers had quit prior to pregnancy (20.5 per cent) or had never smoked more than 100 cigarettes in their lifetime (64.4 per cent). The proportion of mothers who reported any smoking in pregnancy was slightly lower than the 17.4 per cent recorded in the NSW Midwives Data Collection in $2000 .^{3}$

\section{References}

1. Walsh RA, Lowe JB, Hopkins PJ. Quitting smoking in pregnancy. Med J Aust 2001; 175: 320-323.

2. Floreani AA, Rennard SI. The role of cigarette smoke in the pathogenesis of asthma and as a trigger for acute symptoms. Curr Opin Pulmonary Med 1999; 5: 38-46.

3. Public Health Division, NSW Department of Health. NSW Mothers and Babies 2000. N S W Public Health Bull 2001; 13(S-3).

\section{Smoking in the home}

Children are particularly vulnerable to the adverse effects of passive smoking, related to exposure to environmental tobacco smoke, either at home or in other confined spaces.
Parental smoking causes lower respiratory infections, middle ear disease, asthma and sudden infant death syndrome (SIDS) in children. It also exacerbates symptoms of asthma ${ }^{1,2}$.

In the New South Wales Child Health Survey 2001, all parents or carers were asked to describe the smoking status of their household; and, where applicable, to estimate the number of cigarettes smoked inside the house each day. Two-thirds of respondents (65.7 per cent) reported that no one living in their household smoked. A further onequarter (24.1 per cent) reported that smokers living in the household usually or always smoked outside the house. The remaining respondents (10.2 per cent) reported that smokers living in the household sometimes, usually, or always smoked inside the house.

The proportion of parents or carers reporting that their household was smoke-free-that is, where no cigarettes were smoked inside the house each day-was considerably higher (85.6 per cent) than reported in a previous survey of the NSW adult population aged 16 years and over in 1998 (73.2 per cent). ${ }^{3}$ In that same survey, parents with children aged less than six years had the highest smokefree home status (78.0 per cent). ${ }^{4}$

\section{References}

1. Cook DG, Strachan DP. Health effects of passive smoking 10: Summary of effects of parental smoking on the respiratory health of children and implications for research. Thorax 1999; 54: 357-366.

2. Wahlgren DR, Hovell MF, Meltzer EO, Meltzer SB. Involuntary smoking and asthma. Curr Opin Pulm Med 2000; 6: $31-36$

3. Public Health Division 2001. 1997 and 1998 NSW Adult Health Surveys. Electronic Report. Web site: http:// internal.health.nsw.gov.au/public-health/nswhs/index.htm, accessed 11 January 2002.

4. Merom D, Rissel C. Factors associated with smoke-free homes in NSW: Results from the 1998 NSW Health Survey. Aust N Z J Public Health 2001; 25(4): 339-345.

\section{Parental views of child smoking}

Parenting practices that may reduce adolescent smoking include parent-child discussion of smoking, punishment of smoking, restrictive home smoking policies, and rules against smoking. ${ }^{1,2}$

In the New South Wales Child Health Survey 2001, parents or carers of children aged 8-12 years were asked whether they had ever clearly told their child not to smoke, or forbidden their child from smoking. Overall, 62.7 per cent of respondents reported that they had delivered such an anti-smoking message to their child. Parents or carers living in households that included smokers (68.8 per cent) were more likely to report telling their child not to smoke than those from non-smoking households (59.3 per cent). 


\section{FIGURE 4}

\section{POSITION INFANT PLACEDTO SLEEP FROM BIRTH BY URBAN-RURAL AREA HEALTH SERVICE OF}

RESIDENCE, BABIES AGED LESS THAN 12 MONTHS, NSW, 2001
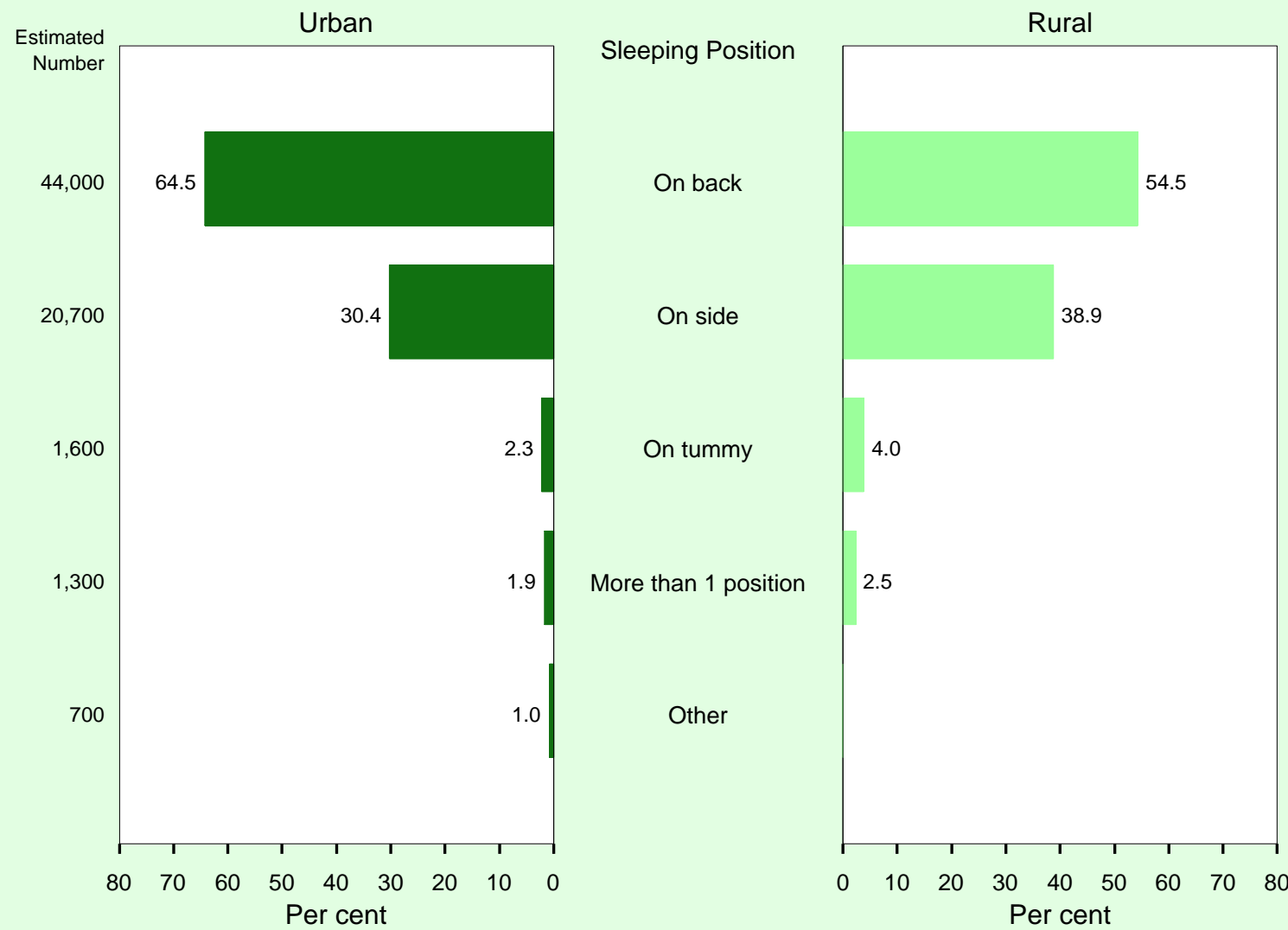

Note: Health areas in Greater Sydney, Hunter, and Illawarra were classified as urban. Estimates based on 736 respondents. Source: New South Wales Child Health Survey 2001 (HOIST). Centre for Epidemiology and Research, NSW Department of Health.

\section{References}

1. Proescholdbell RJ, Chassin L, MacKinnon DP. Home smoking restrictions and adolescent smoking. Nicotine \& Tobacco Research 2000; 2:159-167.

2. Rissel C, McClellan L, Bauman A. Factors associated with delayed tobacco uptake among Vietnamese-Asian and Arabic youth in Sydney, NSW. A N Z J Public Health 2000; 24: 2228.

\section{Infant sleeping position}

Infants placed on their back (supine) to sleep are at the lowest risk of sudden infant death syndrome (SIDS). SIDS is the sudden and unexpected death of an infant, where the death remains unexplained despite complete postmortem examination. ${ }^{1}$ Infants placed on their stomach (prone) to sleep have a much higher risk of SIDS, and those placed on their side also have increased risk, probably because of their tendency to roll into the prone position. ${ }^{2}$ Accordingly, the supine position (placing the infant on its back) is the preferred sleeping position for most healthy infants.
Following a national SIDS prevention campaign, the number of SIDS deaths in NSW has decreased by more than 75 per cent, over the last decade. ${ }^{3}$ Almost all of this decline can be attributed to a reduction in the practice of placing infants in the prone position to sleep. ${ }^{4}$ However, SIDS remains the single most common cause of death in infants in NSW outside the perinatal period, with 44 SIDS deaths in $2000 .^{3}$

In the New South Wales Child Health Survey 2001, mothers of infants aged less than 12 months were asked about the position in which, from birth, their infant was placed for sleep. Just under two-thirds (62.4 per cent) of mothers reported placing their infant on its back to sleep. The remaining mothers reported placing their infant in other sleeping positions: stomach (2.7 per cent), side (32.1 per cent), or other positions ( 0.3 per cent). Mothers from rural areas (54.5 per cent) were less likely than those from urban areas (64.5 per cent) to report placing their infant on its back to sleep (Figure 4).

The proportion of mothers who reported that they placed their infant on its back to sleep (62.4 per cent) was two 


\section{FIGURE 5}

FOLATE TABLETS OR CAPSULES TAKEN BEFORE OR DURING PREGNANCY, MOTHERS WITH BABIES LESS THAN 12 MONTHS OF AGE, NSW, 2001

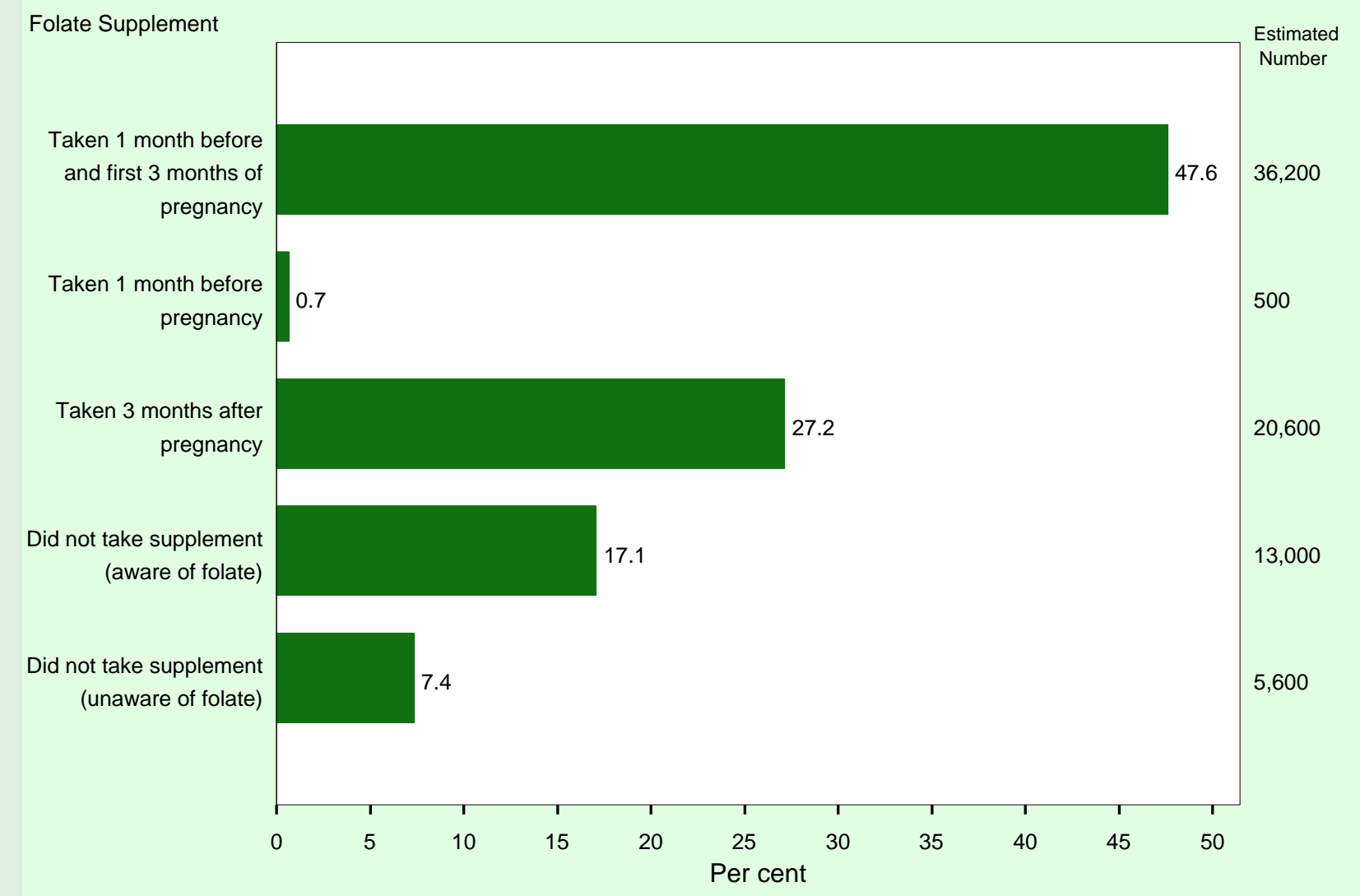

Note: Estimates based on 647 respondents.

Source: New South Wales Child Health Survey 2001 (HOIST). Centre for Epidemiology and Research, NSW Department of Health.

times greater than in a national survey in 1992 (30.8 per cent) ${ }^{5}$ In that survey, most mothers (57.3 per cent) reported placing their infants on their side to sleep.

\section{References}

1. Abraham B, d'Espaignet E, Stevenson C. Australian Health Trends 1995. Canberra: Australian Institute of Health and Welfare, 1996.

2. Scragg RKR, Mitchell EA. Side sleeping position and bed sharing in the sudden infant death syndrome. Ann Med 1998; 30: 345-349.

3. Australian Bureau of Statistics mortality data-deaths registered in NSW (HOIST). Sydney: Centre for Epidemiology and Research, NSW Department of Health, 2000.

4. Dwyer T, Ponsonby AL, Blizzard L, Newman NM, Cochrane JA. The contribution of changes in the prevalence of prone sleeping position to the decline of sudden infant death syndrome in Tasmania. JAMA 1995; 273: 783-789.

5. Australian Bureau of Statistics. Survey of infant sleeping positions. Catalogue no. 4386.0. Canberra: ABS, 1992.

\section{Folate intake during pregnancy}

Folate is a B group vitamin found naturally in foods such as fresh vegetables and fruit, orange juice, legumes, nuts, liver, and yeast. It is also present in fortified products such as breads and breakfast cereals and can be taken in supplement (tablet or capsule) form. An adequate intake of folate around the time of conception can reduce the risk of neural tube defects. ${ }^{1}$ Neural tube defects such as spina bifida, anencephaly and encephalocoele are major causes of disability in children and adults. Neural tube defects are reported in around 80 pregnancies in NSW each year. ${ }^{2}$

In the New South Wales Child Health Survey 2001, mothers of infants aged less than 12 months were asked a series of questions, to assess knowledge about folate and the use of folate supplementation before and during pregnancy. 


\section{Awareness of the link between folate and birth defects}

Approximately two-thirds (61.6 per cent) of mothers of infants aged less than 12 months were aware that the reason for taking additional folate prior to and during pregnancy was to prevent spina bifida or neural tube defects, or to prevent birth defects more generally. This was higher than the 40 per cent of women of childbearing age who knew of the link between folate and birth defects in a series of Australian surveys in 1999. ${ }^{3}$ In another survey of 287 randomly selected recently pregnant women in Western Australia in 1997-1998, approximately two-thirds of women reported that they were aware of the message to increase their folate intake before and early in pregnancy to reduce the risk of spina bifida. ${ }^{4}$

\section{Awareness of dietary sources of folate}

Around two-thirds (69.0 per cent) of respondents named vegetables and one-third (35.0 per cent) named breakfast cereal as foods containing folate, with smaller proportions citing fruit or fruit juice (16.6 per cent) and bread (5.7 per cent). Around one in five mothers (20.6 per cent) could not name any foods that contain folate.

\section{Dietary change to increase folate intake}

Under one-third (27.5 per cent) of mothers of infants aged less than 12 months reported that they had changed their diet to increase folate intake in the month before and/or in the first trimester of pregnancy. A further quarter of mothers (23.4 per cent) reported that they did not change their diet but considered that they already had an adequate folate intake; while the remainder of mothers (48.9 per cent) reported that they did not change their diet, with 84.9 per cent of these being aware of the benefits of folate. Overall, 66.9 per cent of women who did not change their diet were taking folate tablets or capsules.

\section{Use of folate tablets or capsules}

Approximately half (47.6 per cent) of mothers of infants aged less than 12 months reported that they had taken folate tablets or capsules both one month before and in the first trimester of pregnancy, while 27.2 per cent reported that they had taken these supplements in the first trimester, but not prior to pregnancy. One-quarter of respondents (24.5 per cent) reported that they had not taken folate tablets or capsules at all (Figure 5).

\section{References}

1. Lumley J, Watson L, Watson M, Bower C. Periconceptual supplementation with folate and/or multivitamins to prevent neural tube defects and other congenital malformations (Cochrane review). The Cochrane Library 1998. Issue 4. Oxford: Update Software.

2. Public Health Division, NSW Department of Health. NSW Mothers and Babies 2000. N S W Public Health Bull 2001; 13(S-3).
3. Watson MJ, Watson LF. Outcome evaluation of the folateneural tube defect health claim pilot. Australia New Zealand Food Authority, 2000. Web site at www.anzfa.gov.au/ mediareleasespublications/publications/ evaluating thefolateneuraltubedefecthealthclaimpilot/ evaluatingthefolaten1039.cfm, accessed 9 January 2002.

4. Miller M, Bower C, Payne J, Serna P. Folate-related knowledge and practices of Western Australian women before and during pregnancy (Abstract). Tetrology 2000; 62: 367.

\section{Breastfeeding}

Breastfeeding has health advantages for both infants and mothers. For infants, these include protection against diarrhoeal illnesses, respiratory infections, and otitis media; reduced risk of childhood obesity; and improved visual acuity and psychomotor development. For mothers, benefits include quicker recovery from childbirth and reduced risk of ovarian cancer and pre-menopausal breast cancer. ${ }^{1}$

The NHMRC in Australia now recommends exclusive breastfeeding for the first six months of life, in line with a recent revised policy of the World Health Organization (WHO). ${ }^{2}$ Previously, the WHO policy recommended exclusive breastfeeding for 4-6 months, but the benefits of extending the duration have been demonstrated. The NHMRC also recommends that breastfeeding, complimented by appropriate solid foods, should be continued until at least 12 months of age. ${ }^{2}$ According to the WHO definition, exclusively breastfed infants receive only breastmilk (plus medications including vitamins if required).

Recommendations for nationally-standardised monitoring of breastfeeding practices have recently been released, including 11 indicators for the monitoring of breastfeeding. ${ }^{3}$ Data is available from the New South Wales Child Health Survey 2001 for four of these indicators, including the percentage of mothers who ever breastfed, the percentage of mothers who breastfed their infant to any degree for 4-6 months, the median duration of breastfeeding among breastfed infants, and the percentage of those breastfed who were fully breastfed to four months and to six months. This data enable direct comparisons with other states and with forthcoming data from the National Health Survey 2001.

In the New South Wales Child Health Survey 2001, mothers of children aged less than two years were asked a series of questions about breastfeeding and infant feeding practices, which were used to determine the duration of any breastfeeding; and of full breastfeeding (that is consuming only breast milk with or without water). The questions used in the Child Health Survey did not allow measurement of exclusive breastfeeding, as defined by the WHO, as consumption of water, juice, and other nonbreastmilk fluids was not measured. 


\section{FIGURE 6}

DURATION OF BREASTFEEDING CHILDREN AGED LESS THANTWO YEARS, NSW, 2001

Per cent of infants

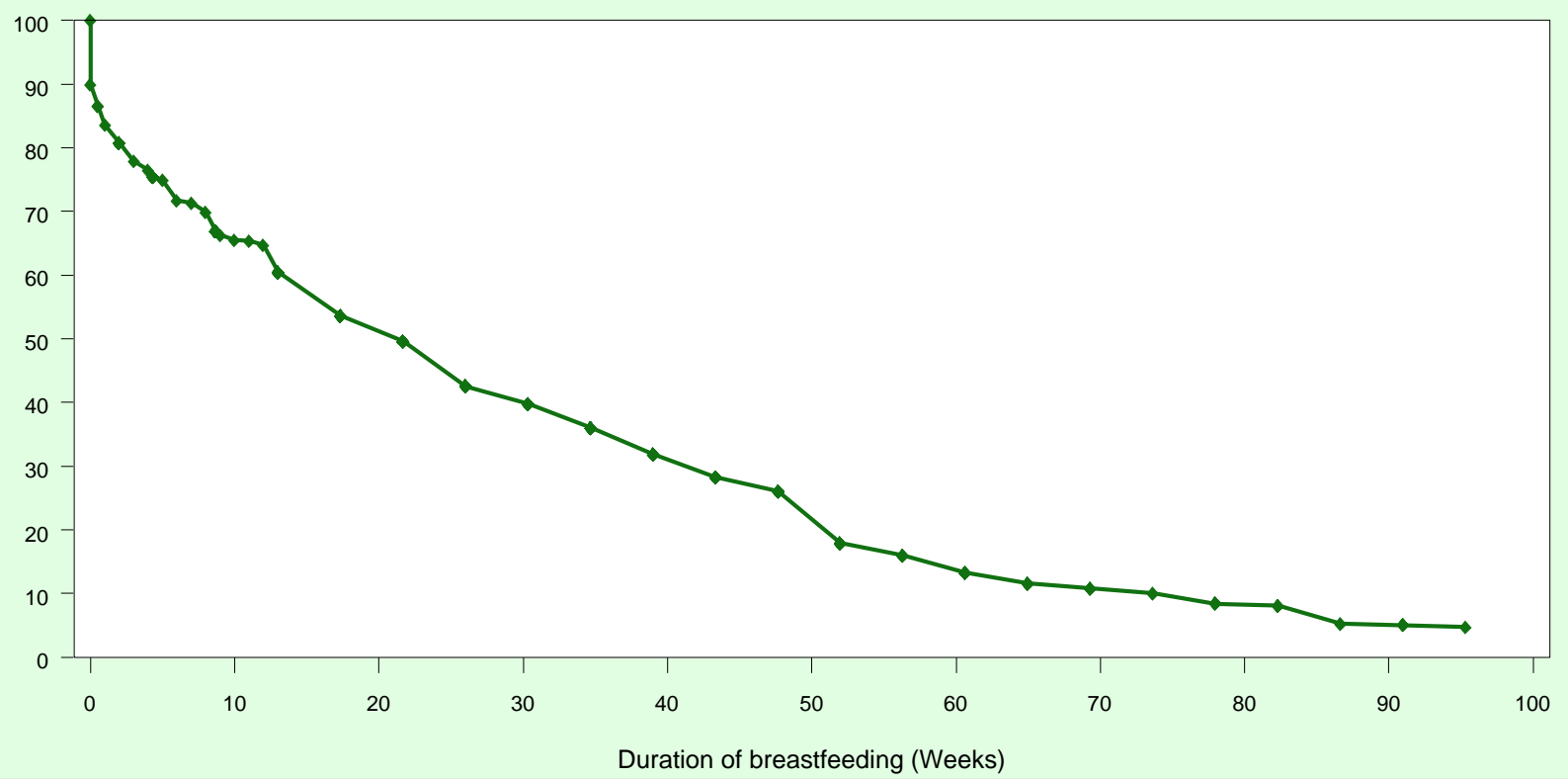

Note: Estimates derived using Kaplan-Meier survival analysis. Estimates based on 1487 respondents.

Source: New South Wales Child Health Survey 2001 (HOIST). Centre for Epidemiology and Research, NSW Department of Health.

\section{Duration of breastfeeding}

Most mothers (89.8 per cent) reported that their infant had been breastfed. However, many mothers breastfed for a short period. Only 76.5 per cent of mothers were breastfeeding at four weeks, 60.5 per cent were breast feeding at three months, 42.6 per cent were breastfeeding at six months, and only 17.9 per cent were still breastfeeding at 12 months (Figure 6). A higher proportion of mothers with tertiary level education ( 96.3 per cent) than mothers with less-than tertiary level education (86.5 per cent), reported that their infant was ever breastfed.

The proportion of mothers reporting that they breastfed for at least one week (83.7 per cent) was slightly higher than the 78.4 per cent of NSW mothers who reported breastfeeding at hospital discharge in the 1995 National Health Survey. ${ }^{4}$ The proportion of NSW mothers in the latter survey who reported that they were still breastfeeding at three months (60.0 per cent) and six months (44.0 per cent) was similar to the New South Wales Child Health Survey 2001.

\section{Full breastfeeding}

Infants who are fully breastfed receive breastmilk as the main source of nourishment. This includes infants who are exclusively breastfed-that is, who receive only breastmilk with no water, other liquids, or solids (except for vitamins, mineral supplements, or medicines); and infants who are predominantly breastfed-that is who receive breastmilk as well as other fluids including water, water-based drinks, or fruit juice, but not breastmilk substitutes or solids. Therefore, the fully breastfed rate is the combined rate of exclusively breastfed and predominantly breastfed. ${ }^{3}$

With regard to full breastfeeding, half of mothers (52.7 per cent) reported that their infant was fully breastfed at three months of age. Less than four in 20 mothers (15.1 per cent) reported that their infant was fully breastfed at six months of age.

These proportions were lower than the NSW estimates for 'exclusive' breastfeeding at three months (56.6 per cent) and six months (17.2 per cent) reported in the 1995 National Health Survey. ${ }^{4}$ However, a different definition was used in that survey whereby infants who were regularly consuming large amounts of fruit juice, and also receiving other food on an irregular basis were still classified as being 'exclusively' breastfed.

\section{Main reasons for breastfeeding}

Mothers of children aged less than two years who reported any breastfeeding were asked to report the main reason they breastfed. The main reasons cited were that breastmilk is better for the infant ( 95.2 per cent), it prevents allergies (65.4 per cent), it is the right thing to do (60.6 per cent), it is cheaper ( 57.7 per cent), other people advised me to 


\section{FIGURE 7}

USUAL DAILY CONSUMPTION OF FRUIT AND VEGETABLES BY AGE GROUP, CHILDREN AGED 2-12 YEARS, NSW, 2001
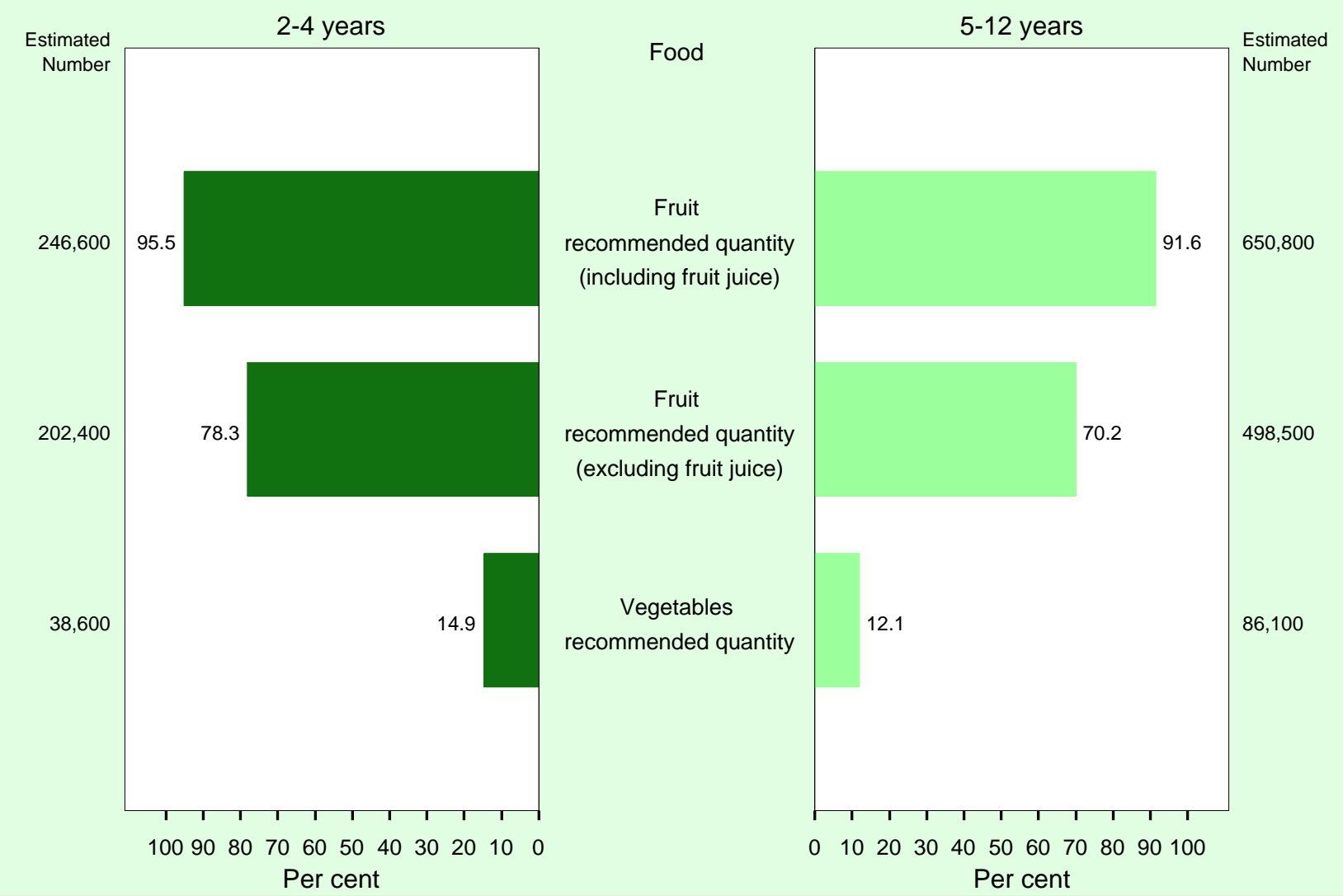

Note: Definitions of serves and the recommended number of serves are based on The Australian guide to healthy eating. (Commonwealth Department of Health and Family Services, 1998). Estimates based on 7916 respondents.

Source: New South Wales Child Health Survey 2001 (HOIST). Centre for Epidemiology and Research, NSW Department of Health.

breastfeed (37.1 per cent), breastfeeding helps weight loss following pregnancy (28.7 per cent) and the infant's father wanted me to breastfeed (26.3 per cent).

\section{References}

1. National Health and Medical Research Council. Draft dietary guidelines for children and adolescents. Canberra: AusInfo, 2001.

2. World Health Organization. Nutrition and Infant Feeding. Web site at www.who.int/child-adolescent-health/ NUTRITION/infant.htm, accessed 11 January 2002.

3. Webb K, Marks G, Lund-Adams M, Rutishauser IHE, Abraham B. Towards a national system for monitoring breastfeeding in Australia: Recommendations for population indicators, definitions, and next steps. Canberra: Australian Food and Nutrition Monitoring Unit, Commonwealth Department of Health and Aged Care, 2001.

4. Donath S, Amir LH. Rates of breast-feeding in Australia by state and socioeconomic status: Evidence from the 1995 National Health Survey. J Paediatr Child Health 2000; 36: 164-168.

\section{Food intake}

Many dietary factors are linked to health and disease, either as protective influences or as risk factors. Diet contributes substantially to risk of or protection from many common chronic diseases, including: coronary heart disease, stroke, cancer, diabetes mellitus, osteoporosis, dental caries, gall bladder disease, diverticular disease. Healthy diets in childhood are important, not only because they shape diets in later life but because many chronic diseases, including cardiovascular diseases and osteoporosis, may have their beginnings in childhood.,

The current sources of dietary recommendation for Australian children are the Draft dietary guidelines for children and adolescents and infant feeding guidelines and the Australian guide to healthy eating. ${ }^{3,4,5}$ The Australian guide to healthy eating recognises different eating patterns, by providing different recommendations for diets based largely on breads and cereals and for diets that include more of all food groups. Its recommendations vary by age and sex. 


\section{FIGURE 8}

USUAL CONSUMPTION OF MILK, BY AGE GROUP, CHILDREN AGED 2-12 YEARS, NSW, 2001
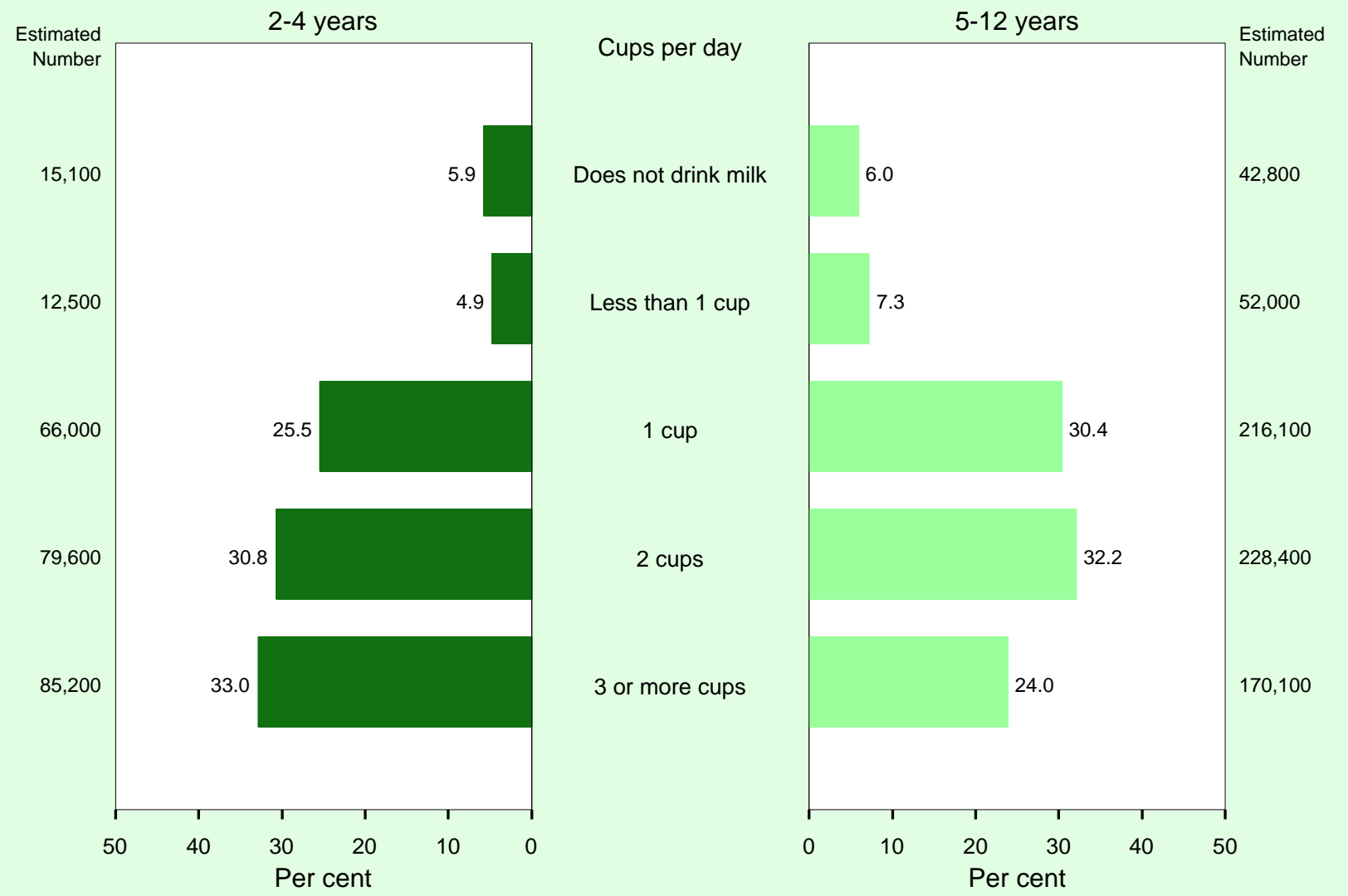

Note: Milk refers to cow's milk only. Estimates based on 7916 respondents.

Source: New South Wales Child Health Survey 2001 (HOIST). Centre for Epidemiology and Research, NSW Department of Health.

The New South Wales Child Health Survey 2001 included questions about consumption of specific foods that relate to protective and high risk dietary factors: fruit, vegetables, milk, fruit juice, soft drinks, and hot chips or french fries.

Fruit and vegetables are a significant source of antioxidants, mainly vitamins and minerals, which play an important role in removing damaging 'free radicals' formed during normal metabolism. Evidence suggests that antioxidant nutrients play an important protective role in many diseases, including cardiovascular and eye diseases. ${ }^{6}$

\section{TABLE 7}

MINIMUM RECOMMENDED DAILY SERVES OF FRUIT AND VEGETABLES NEEDEDTO ACHIEVE A HEALTHY DIET FOR CHILDREN, BY AGE GROUP ${ }^{4}$

\begin{tabular}{|lcc|}
\hline Age group & Serves of fruits & Serves of vegetables \\
\hline $2-7$ years & 1 & 2 \\
$8-11$ years & 1 & 3 \\
12 years & 3 & 4 \\
\hline
\end{tabular}

Fruit and vegetables are also important sources of dietary fibre, complex carbohydrates and folate. An increase in their consumption will most likely result in a corresponding decrease in fat intake.

Milk is an excellent source of many nutrients, including calcium, protein, riboflavin, and vitamin B12. ${ }^{3}$ Calcium is important for bone growth and for attaining peak bone mass at adolescence, which protects against osteoporosis and fractures in later life. ${ }^{2}$

Fruit juice is a good source of vitamins such as vitamin C and folate, and one-half cup of juice supplies one daily serve of fruit. However, because most fruit juices contain added sugars and little fibre, they should not be used as a substitute for fresh fruits. ${ }^{3}$ Increasing juice consumption among children in recent years has been accompanied by reduced consumption of milk (and hence calcium). Additionally, excessive consumption of fruit juice has been associated with carbohydrate malabsorption, nonspecific chronic diarrhoea, and failure to thrive, as well as excessive energy intake and obesity. Nursing-related 


\section{FIGURE 9}

\section{CONSUMPTION OF SELECTED FOODS BY AGE GROUP, CHILDREN AGED 2-12 YEARS, NSW, 2001}
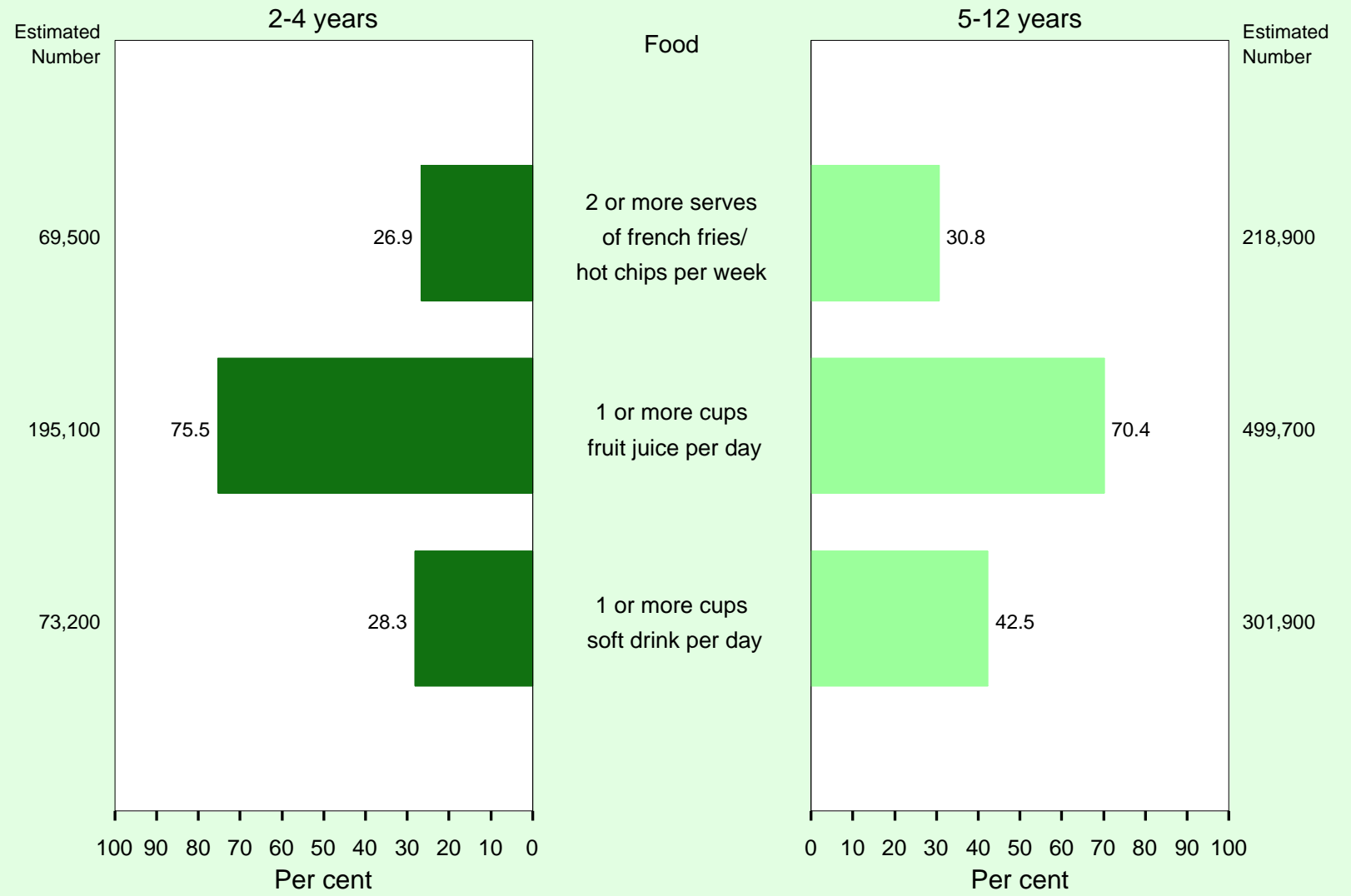

Note: Estimates based on 7916 respondents.

Source: New South Wales Child Health Survey 2001 (HOIST). Centre for Epidemiology and Research, NSW Department of Health.

bottle caries may also result from prolonged feeding of fruit juice to infants and young children from bottles. ${ }^{7.8}$

Soft drinks, cordials and sports drinks contain large amounts of sugar and energy. Consumption of these beverages can adversely affect nutrition by displacing milk and fruit juices in the diet. ${ }^{3}$ Excessive consumption of soft drinks has been associated with childhood obesity and increases the risk of dental caries. ${ }^{7,8,9}$ Consumption of carbonated drinks, particularly cola drinks, may increase the risk of bone fractures in adolescent females. ${ }^{10}$

Hot chips or french fries are a high-fat food commonly consumed by children both at home and away from home. Excessive fat intake contributes to overweight and obesity among children, which may lead to the development of a range of chronic diseases, including cardiovascular disease, diabetes mellitus, cancer, musculoskeletal problems, and psychological problems. ${ }^{11}$ Potato chips contribute around eight per cent of total fat intake of children aged 2-12 years. ${ }^{3}$ Limiting the use of fried foods such as hot chips and french fries, and choosing lower fat foods when eating at fast food restaurants, are suggested as ways to foster positive practices related to moderation of fat intake in children. ${ }^{12}$

\section{Fruit and vegetables}

The minimum recommendations for daily consumption of fruit and vegetables used in analysis of the New South Wales Child Health Survey 2001 are shown in Table 7. These were based on the Australian guide to healthy eating. ${ }^{4}$ However, the Australian guide to healthy eating gives no recommendations for children aged 2-3 years, so we applied the recommendations for children aged 4-7 years to children aged 2-3 years.

In the New South Wales Child Health Survey 2001, one serve of fruit was calculated as half-a-piece of fruit, onethird of a cup of canned fruit, or one tablespoon of dried fruit. Since the Australian guide to healthy eating stated that the recommended serve of fruit was one medium piece of fruit, two small pieces of fruit, a cup of diced canned fruit, half a cup of juice, or one-and-a half tablespoons of dried fruit, we converted our serves to this standard by dividing them by two. 
In the New South Wales Child Health Survey 2001, most (92.7 per cent) children aged 2-12 years, (95.5 per cent of children aged 2-4 years, and 91.6 per cent of children aged 5-12 years) were reported to consume the recommended daily minimum quantity of fruit, including fruit juice (Figure 7). However, around 60 per cent of the serves of fruit consumed by children were in the form of fruit juice. Because most fruit juices contain added sugars and little fibre, they are not recommended as a substitute for fresh fruits. ${ }^{3}$ If fruit juice was excluded, the proportion of children reported to consume the recommended minimum daily quantity of fruits dropped considerably, to 78.3 per cent among children aged $2-4$ years and 70.2 per cent among children aged 5-12 years, or 72.4 per cent overall.

In the New South Wales Child Health Survey 2001, one serve of vegetables was calculated as a quarter of a cup of salad or four sticks of vegetables. Since the Australian guide to healthy eating recommended that one serve of vegetables was one cup of salad or vegetables, we converted our serves to this standard by dividing them by four. In the New South Wales Child Health Survey 2001, 12.9 per cent of all children aged 2-12 years, or less than one in seven children aged 2-4 years (14.9 per cent) and 5-12 years (12.1 per cent) were reported to consume the recommended daily minimum quantity of vegetables.

Fruit and vegetable intake, as measured on one day, in the National Nutrition Survey: Foods eaten Australia 1995, showed that high a proportion of children ate no fruit on the day of the survey: around one third of children aged under 12 years did not eat fruit or fruit products. ${ }^{13}$ However, this survey did not measure 'usual' consumption of fruit and vegetables among children, so the proportion of children consuming no fruit, or meeting recommended serves, cannot be directly compared with the results of the New South Wales Child Health Survey 2001.

\section{Milk}

The minimum daily number of serves of dairy products recommended in the Australian guide to healthy eating is two serves for children aged 4-11 years and three serves for children aged 12 years. ${ }^{4}$ One cup of milk $(250 \mathrm{~mL})$ provides one serve.

In the New South Wales Child Health Survey 2001, parents or carers were asked about consumption of milk, but not about other dairy products. A high proportion of children aged 2-4 years (89.3 per cent) and 5-12 years (86.6 per cent) were reported to drink one or more cups of milk per day. Among children aged 2-4 years, approximately onequarter (25.5 per cent) were reported to drink one cup of milk per day, while a greater proportion were reported to drink two cups per day (30.8 per cent) or three or more cups per day (33.0 per cent). Milk consumption was lower among older children, with around one-third of children aged 5-12 years reported to drink one cup of milk per day (30.4 per cent) or two cups per day (32.2 per cent), while one-quarter were reported to drink three or more cups per day (24.0 per cent) (Figure 8).

Almost two-thirds of children aged 2-4 years (63.8 per cent) and more than half of children aged 5-12 years (56.2 per cent) were reported to be meeting the recommended amounts for dairy products from milk alone. The remaining children may still have been meeting the recommended amounts through consumption of other dairy products such as cheese and yoghurt.

\section{Fruit juice}

More than three-quarters of children aged 2-4 years (75.5 per cent) and a slightly smaller proportion of children aged 5-12 years (70.4 per cent) were reported to drink at least one cup of fruit juice per day (Figure 9). Among children aged 0-4 years, similar proportions were reported to drink one cup of juice per day (28.3 per cent), two cups per day (23.4 per cent) or three or more cups per day (24.0 per cent). Consumption of fruit juice was lower among older children, with around one-third of children aged 5-12 years reported to drink one cup of fruit juice per day (33.2 per cent), and smaller proportions reported to drink two cups per day (21.8 per cent), or three or more cups per day (15.5 per cent).

\section{Soft drinks, cordials and sports drinks}

Just over one-quarter of children aged 2-4 years (28.3 per cent) were reported to drink at least one cup of soft drink, cordial or sports drinks per day, with 12.9 per cent reported to drink two or more cups per day. Children aged 5-12 years consumed more of these drinks, with 42.5 per cent reported to consume one or more cups per day, and half of these (22.1 per cent) reported to drink two or more cups per day (Figure 9).

\section{Hot chips or french fries}

In the New South Wales Child Health Survey 2001, one serve of hot chips or french fries was calculated as half a cup of chips or french fries. Potato chips or french fries were commonly consumed by children. Only 10.1 per cent of children aged 2-4 years and 7.4 per cent of children aged 5-12 years were reported to not eat hot chips or french fries. Around two-thirds of children aged 2-4 years (65.6 per cent) and 5-12 years ( 68.8 per cent) were reported to eat at least one serve of hot chips or french fries per week. Around one-quarter (26.9 per cent) of children aged 2-4 years ate two or more serves of hot chips compared with around one-third (30.8 per cent) of children aged 5-12 years (Figure 9). Only around one in 10 were reported to eat three or more serves each week with this proportion being higher for children aged 5-12 years (12.2 per cent) compared with 8.4 per cent of children aged $2-4$ years.

\section{References}

1. Van Horn L, Greenland P. Prevention of coronary artery disease is a pediatric problem. JAMA 1997; 278: 1779-1780. 
2. Mascarenhas MR, Tershakovec AM, Stettler N. Nutrition interventions in childhood for the prevention of chronic diseases in adulthood. Curr Opin Pediatr 1999; 11:598-604.

3. National Health and Medical Research Council. Draft dietary guidelines for children and adolescents and infant feeding guidelines. Canberra: AusInfo, 2001.

4. Commonwealth Department of Health and Family Services. Australian guide to healthy eating. Canberra: Commonwealth Department of Health and Family Services, 1998.

5. Dennison BA. Fruit juice consumption by infants and children: a review. J Am Coll Nutr 1996; 15: 4S-11S.

6. Machlin L. Critical assessment of epidemiological data concerning the impact of antioxidant nutrients on cancer and cardiovascular disease. Crit Rev Food Sci Nutr, 1995; 35: 41-50.

7. Dennison BA. Fruit juice consumption by infants and children: a review. J Am Coll Nutr 1996; 15: 4S-11S.

8. Watt RG, Dykes J, Sheiham A. Preschool children's consumption of drinks: Implications for dental health. Community Dent Health 2000; 17: 8-13.

9. Ludwig DS, Peterson KE, Gortmaker SL. Relation between consumption of sugar-sweetened drinks and childhood obesity: a prospective, observational analysis. Lancet 2001; 357: 490-491.
10. Wyshak G. Teenaged girls, carbonated beverage consumption, and bone fractures. Arch Pediatr Adolesc Med 2000; 154: 610-613.

11. Wabitsch M. Overweight and obesity in European children: Definition and diagnostic procedures, risk factors and consequences for later health outcome. Eur J Pediatrics 2000; 159: S8-S13.

12. Reid J, George J, Pears R. Food and nutrition guidelines for children aged 2-12 years. Auckland: New Zealand Department of Health, 1992.

13. Australian Bureau of Statistics and Commonwealth Department of Health and Family Services. National Nutrition Survey: Foods eaten Australia 1995. Catalogue no. 4804.0. Canberra: ABS, 1999.

\section{Food security and hunger}

Food security is considered to exist when an adequate amount of nutritionally-appropriate and personallyacceptable food is available, and is able to be acquired in socially acceptable ways. Lack of food security endangers physical health through malnutrition and affects psychological wellbeing. If periodic, it may be associated

\section{FIGURE 10}

\section{EVER RAN OUT OF FOOD IN THE LAST 12 MONTHS BY AREA HEALTH SERVICE OF RESIDENCE, HOUSEHOLDS WITH CHILDREN AGED 0-12 YEARS, NSW, 2001}

Health Area

Central Sydney

Northern Sydney

Western Sydney

Wentworth

South-West Sydney

Central Coast

Hunter

Illawarra

South-East Sydney

Northern Rivers

Mid-North Coast

New England

Macquarie

Mid-Western

Far West

Greater Murray

Southern

All NSW
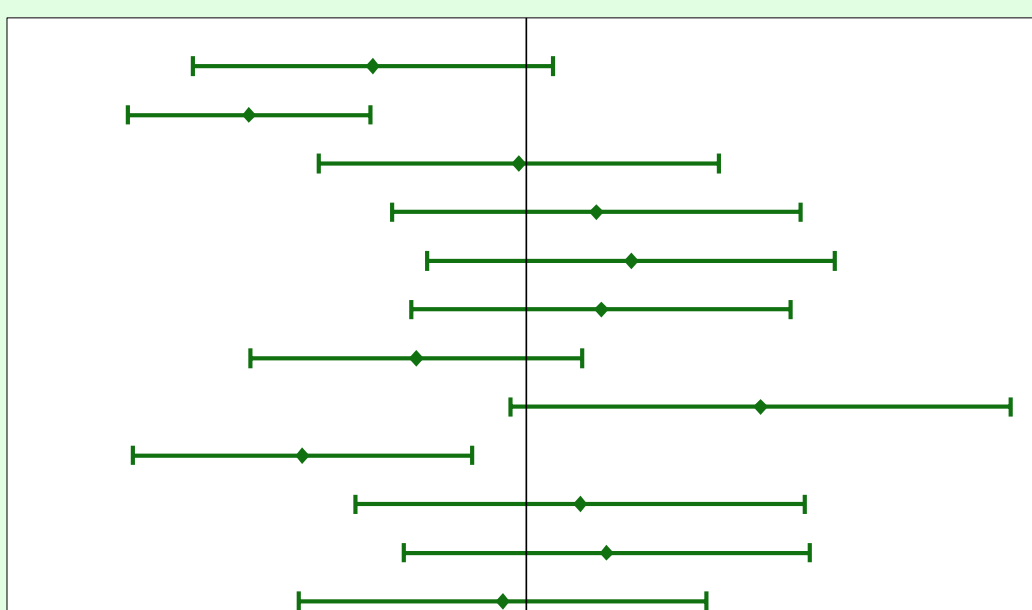

0
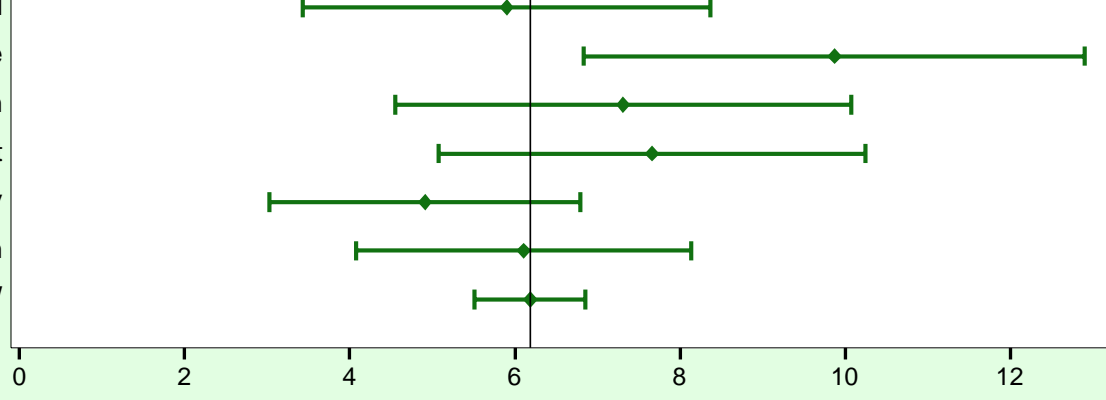

6

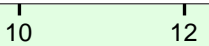

14

Per cent

Note: Estimates based on 9425 respondents.

Source: New South Wales Child Health Survey 2001 (HOIST). Centre for Epidemiology and Research, NSW Department of Health. 


\section{TABLE 8}

EVER RAN OUT OF FOOD IN THE LAST 12 MONTHS BY AREA HEALTH SERVICE OF RESIDENCE, HOUSEHOLDS WITH CHILDREN AGED 0-12 YEARS, NSW, 2001

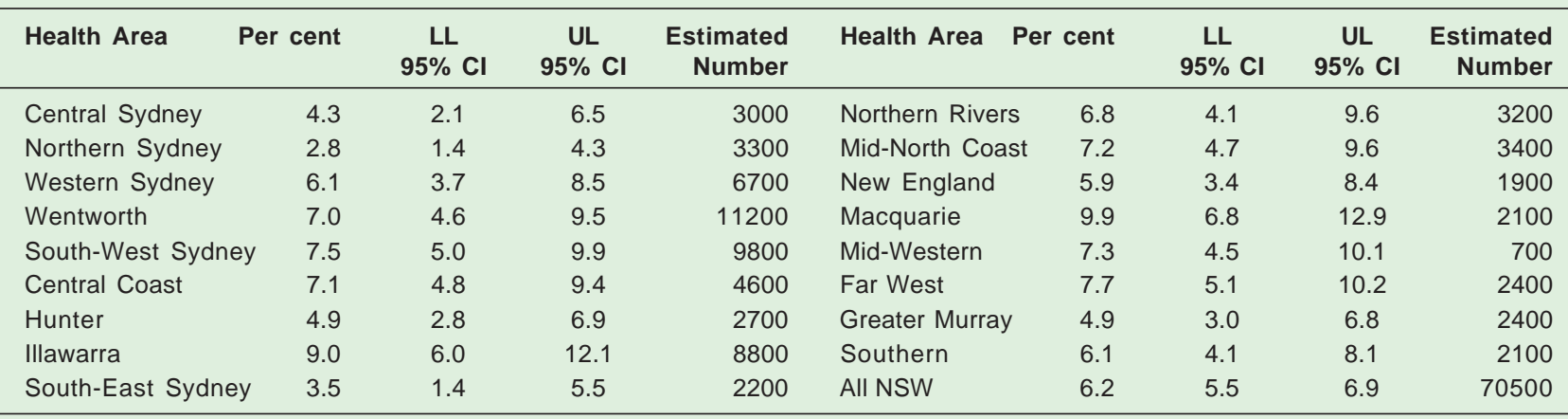

Note: Estimates based on 9425 respondents.

Source: New South Wales Child Health Survey 2001 (HOIST). Centre for Epidemiology and Research, NSW Department of Health.

with cyclical weight gain and weight loss, and with obesity. ${ }^{1}$ At the household level, the consequences of food insecurity include disruption of eating patterns and eating rituals; at the broader societal level, they include reduced productivity and threat to harmonious community life. ${ }^{2}$

In the New South Wales Child Health Survey 2001, all parents or carers were asked whether there were any times in the last 12 months that they had run out of food and could not afford to buy more. Those who reported that this had happened were asked a further series of questions about how this had affected their ability to feed their children.

Overall, 6.2 per cent of respondents reported that they had run out of food and couldn't afford to buy more, on at least one occasion, in the last 12 months. This proportion varied among area health services, from 2.8 per cent in Northern Sydney Health Area to 9.9 per cent in Macquarie Health Area (Figure 10, Table 8). The overall proportion was higher than that reported in the National Nutrition Survey: Foods eaten Australia 1995, where 5.0 per cent of adults aged over 19 years reported that they had run out of food and could not afford to buy more. ${ }^{3}$

Among respondents who had run out of food, threequarters (74.6 per cent) reported that, as a result, they ate the same thing for several days in a row. Smaller proportions of these parents or carers reported that their children were not fed balanced meals ( 43.7 per cent), were not eating enough (25.5 per cent), or were sometimes hungry (32.3 per cent).

\section{References}

1. Parnell WR, Reid J, Wilson NC, McKenzie J, Russell DG. Food security: Is New Zealand a land of plenty? New Zealand Medical Journal 2001: 114: 141-145.
2. Hamelin A, Habicht J, Beaudry M. Food insecurity: consequences for the household and broader social implications. J Nutr 1999; 129: S525-S528.

3. Australian Bureau of Statistics and Commonwealth Department of Health and Family Services. National Nutrition Survey: Selected highlights Australia 1995. Catalogue no. 4802.0. Canberra: ABS, 1997.

\section{Sun protection}

Australia has the highest incidence of skin cancer in the world and melanoma is the third most common potentially fatal cancer in Australia. Unprotected exposure to solar ultra-violet radiation (UVR) is the primary modifiable risk factor in the development of skin cancer. Childhood exposure to UVR has been shown to be particularly important in increasing the risk of skin cancer later in life. ${ }^{1}$

Sun protection behaviours play a key role in minimising the risk of developing skin cancer. The Slip, Slop, Slap ('slip on a shirt, slop on some sunscreen and slap on a hat') sun protection message has been promoted throughout Australia for over 20 years. ${ }^{1}$ In addition to this campaign, the more recent SunSmart campaign, adopted first in Victoria in 1988 through the Anti-Cancer Council, promotes sunlight avoidance by staying indoors during certain times of the day and wearing protective clothing to prevent exposure to UVR. ${ }^{2}$

In the New South Wales Child Health Survey 2001, all parents or carers were asked to identify actions they could take to reduce their child's risk of getting skin cancer. Respondents of children aged 12 months and over were also asked to describe their use of sun protection measures, and whether their child had been sunburnt, last summer. 


\section{FIGURE 11}

\section{USE OF HATS, SUNSCREEN AND PROTECTIVE CLOTHING LAST SUMMER BY AGE GROUP, CHILDREN}

AGED 1-12 YEARS, NSW, 2001

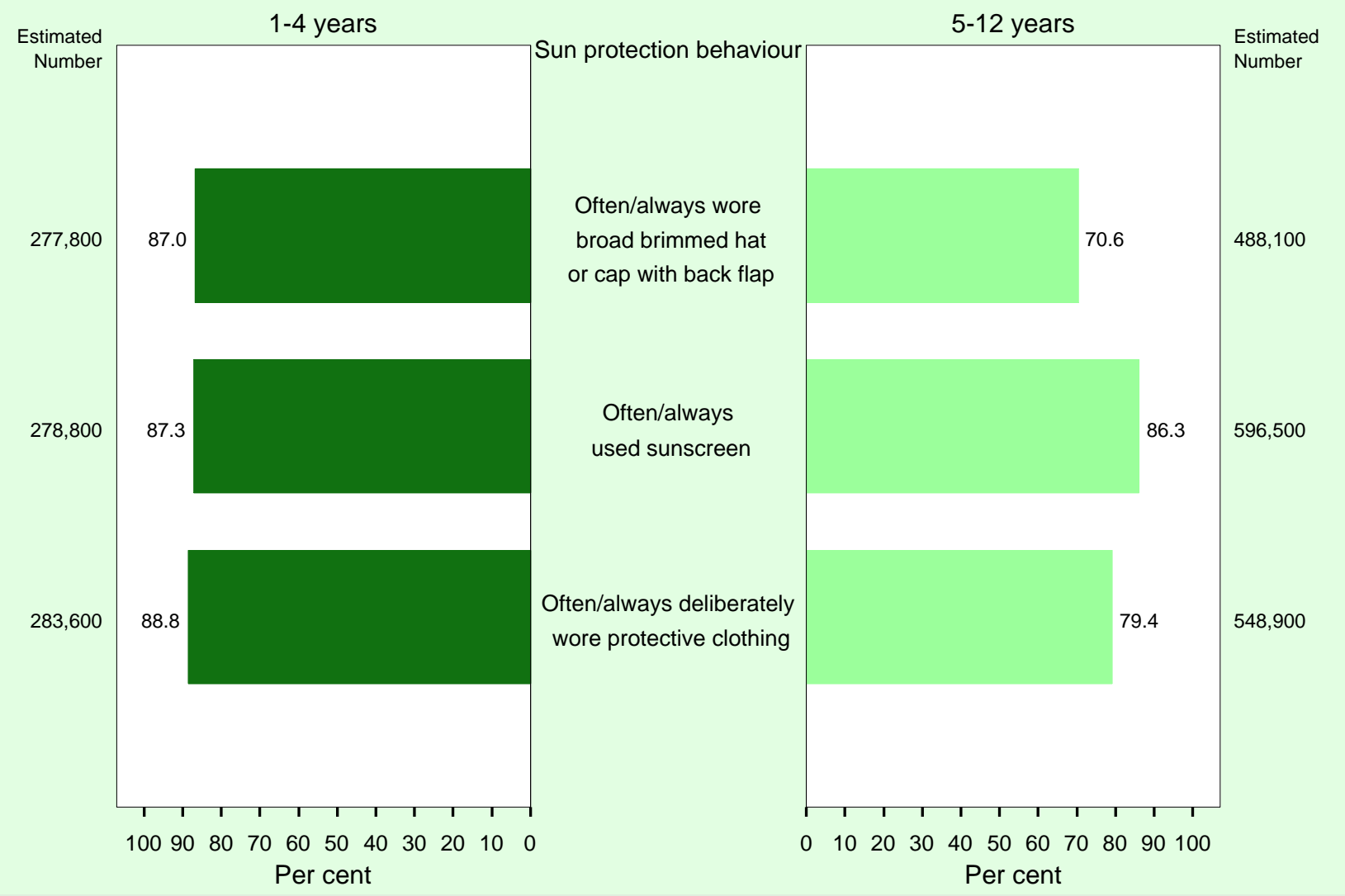

Note: Estimates based on 8372 children who were ever in the sun for at least 15 minutes between 11.00 a.m. and 3.00 p.m.

Source: New South Wales Child Health Survey 2001 (HOIST). Centre for Epidemiology and Research, NSW Department of Health.

\section{Awareness of sun protection measures}

When asked to name steps they could take to reduce their child's risk of getting skin cancer, most parents or carers mentioned applying sunscreen ( 94.3 per cent) and wearing a broad-brimmed hat or cap with flap (81.3 per cent). A smaller proportion mentioned wearing protective clothing (67.9 per cent). Less than one-quarter mentioned not going outside in the middle of the day (22.9 per cent); even fewer mentioned staying in the shade (16.7 per cent); while only 6.4 per cent mentioned wearing sunglasses.

\section{Use of sun protection measures}

When out in the sun for 15 minutes or more in the previous summer. Most children aged 1-12 years were reported to have worn a broad-brimmed hat or cap with a flap (75.8 per cent), often or always used sunscreen (86.6 per cent), and worn protective clothing ( 82.4 per cent). Reported use of sunscreen was similar among children aged 1-4 and 5-12 years. However, smaller proportions of children aged 5-12 years were reported to have often or always worn a broad-brimmed hat or cap with a flap (70.6 per cent) or protective clothing (79.4 per cent) (Figure 11).

\section{Frequency of sunburn}

More than one-third (35.6 per cent) of children aged 1-12 years were reported, in the previous summer, to have been sunburnt to the point where their skin was still sore and tender the next day. This proportion was slightly higher among females ( 37.9 per cent) than males (33.5 per cent). More children from rural areas (41.7 per cent) were reported to have had at least one episode of sunburn, compared with children from urban areas (33.7 per cent). Less than 4.0 per cent of children from both rural and urban areas were reported to have been sunburnt three or more times in the previous summer.

\section{References}

1. National Health and Medical Research Council. Primary prevention of skin cancer in Australia. Canberra: NHMRC, 1996.

2. SunSmart Web site at www.sunsmart.com.au, accessed 21 May 2002. 
FIGURE 12

PLACES WHERE CHILD WAS RESCUED, CHILDREN AGED 0-12 YEARS, WHO HAD EVER BEEN RESCUED FROM DROWNING. NSW. 2001

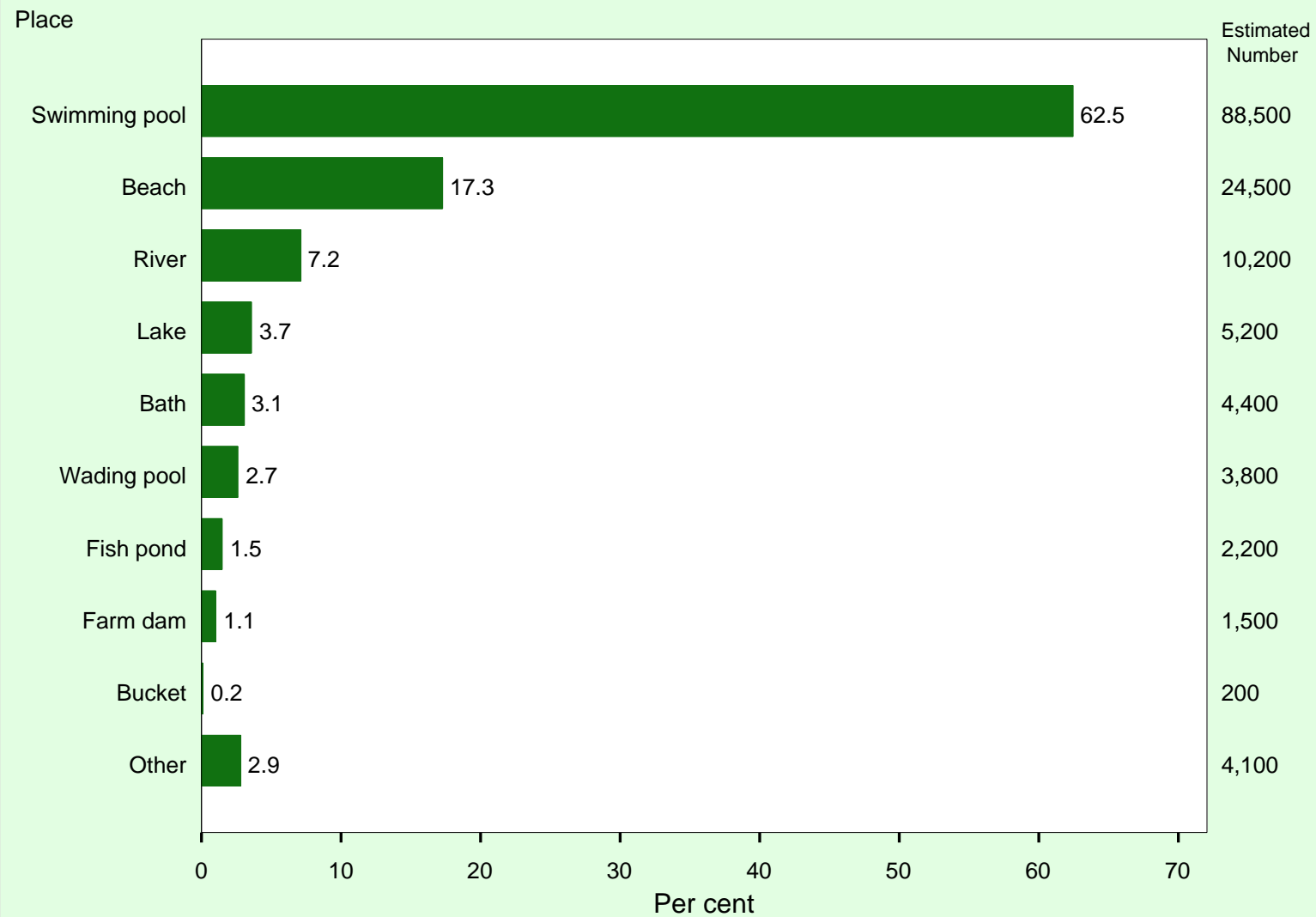

Note: Respondents could nominate more than one place. Percentages will total more than 100. Estimates based on 1157 respondents.

Source: New South Wales Child Health Survey 2001 (HOIST). Centre for Epidemiology and Research, NSW Department of Health

\section{Water safety: Drowning}

There were 16 unintentional drownings of children aged under five years in NSW in 1999, and an estimated 14 in 2000 , representing about one in five unintentional drownings across all age groups. Around two-thirds of drownings occur in males. ${ }^{1}$ Swimming pools are the most common location for drowning in children, followed by lakes, lagoons or waterholes, and bathtubs. ${ }^{2}$

In the New South Wales Child Health Survey 2001, all parents or carers were asked whether their child had ever been rescued from drowning in any body of water, including a beach, river, bath, bucket, pond, or wading pool. Respondents were not asked whether their child had required medical assistance or had signs and symptoms of injury from drowning.

Overall, more than one in 10 children aged $0-12$ years (12.4 per cent) were reported to have been rescued from drowning. This proportion was higher among children aged 5-12 years (14.8 per cent) compared with children aged $0-4$ years (8.5 per cent), and higher among males
(13.0 per cent) than females ( 11.8 per cent). It was slightly higher among children from rural areas (13.3 per cent), compared with those from urban areas (12.1 per cent).

By far the most common places from which children had been rescued were swimming pools (62.5 per cent of rescues), followed by beaches (17.3 per cent) and rivers (7.2 per cent) (Figure 12). Less than five per cent of reported rescues were from bathtubs, lakes, wading pools, or other bodies of water.

\section{References}

1. Public Health Division. The health of the people of NSWReport of the Chief Health Officer 2002. Sydney: NSW Department of Health, 2002.

2. Moon L, Rahman N, Bhatia K. Australia's children: Their health and wellbeing 1998. AIHW Catalogue no. PHE 7. Canberra: Australian Institute of Health and Welfare, 1998. 


\section{FIGURE 13}

SPORTS AND ACTIVITIES PLAYED INTHE LAST 12 MONTHS BY SEX, CHILDREN AGED 5-12 YEARS, NSW, 2001

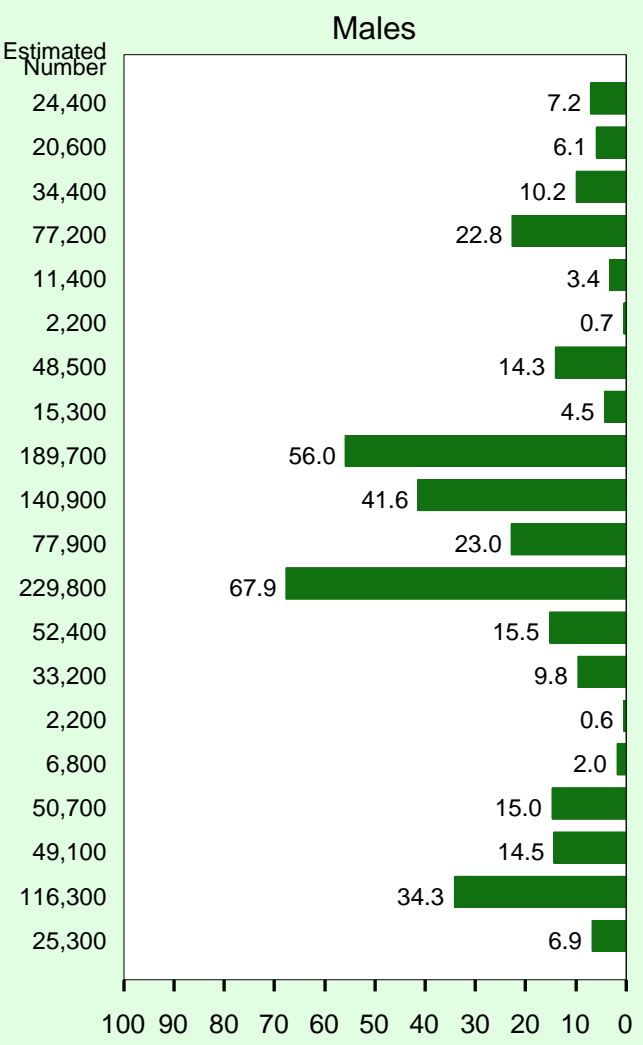

Per cent

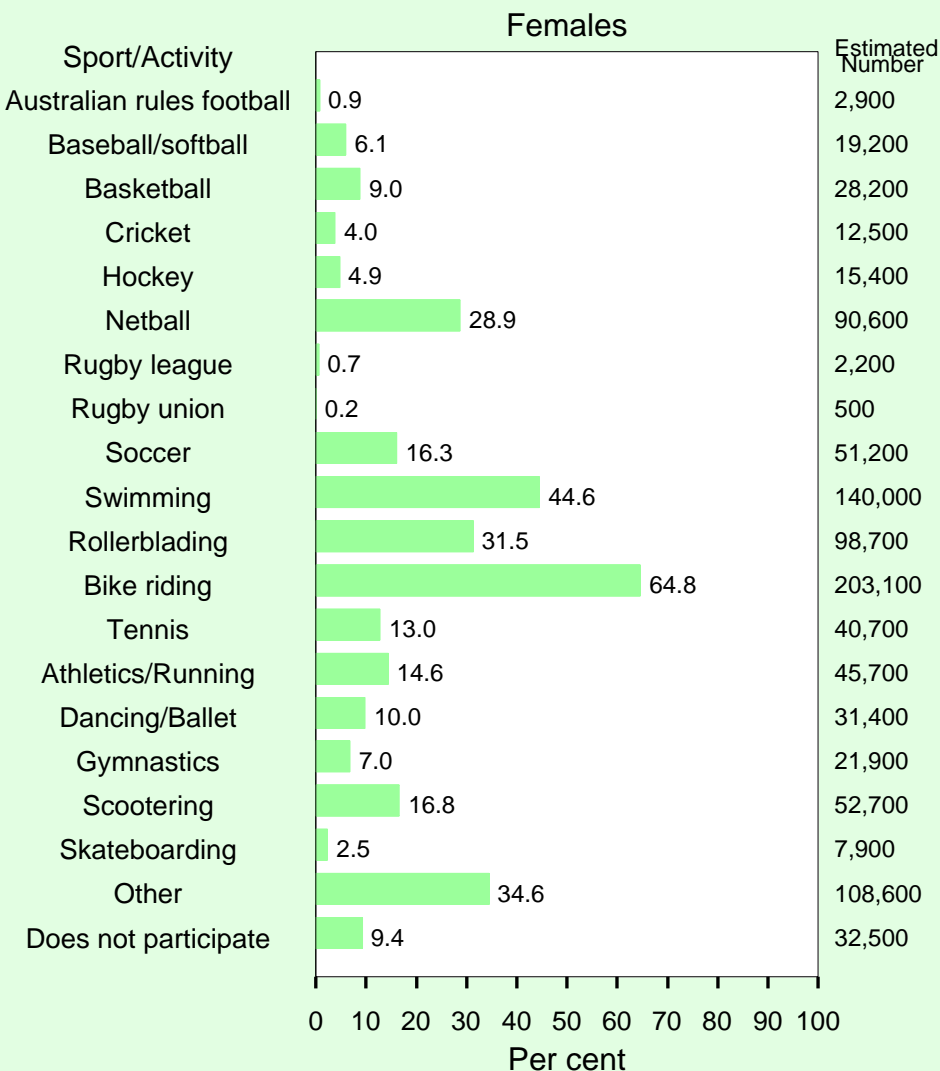

Per cent

Note: Respondents could list more than one sport or activity. Percentages will total more than 100 . Estimates based on 5888 respondents.

Source: New South Wales Child Health Survey 2001 (HOIST). Centre for Epidemiology and Research, NSW Department of Health.

\section{Physical activity and inactivity}

Weight-bearing physical activity in childhood is associated with higher bone mineral density and reduced risk of osteoporosis in adulthood. ${ }^{1}$ Physical activity may also have positive effects on blood lipids, blood pressure, body composition, glucose metabolism, and the psychological health of children. ${ }^{2}$ Additionally, an active lifestyle during childhood is likely to assist in establishing activity patterns that will continue into adulthood, with consequent reduction in the risk of obesity, cardiovascular disease, diabetes, cancer of the colon, and osteoporosis, all of which may have their beginnings in childhood.

Factors associated with higher levels of activity in childhood and adolescence include: access to facilities and programs; participation in sports; time spent outdoors; and perceived competence at physical activities. Factors associated with lower levels of activity include: being sedentary after school and on weekends, and depression. ${ }^{2}$ Booth et al. constructed three categories of physical activity in children for a school-based survey in NSW in 1997. ${ }^{3}$ The categories were: active (participation in at least 3.5 hours moderate intensity activity over at least five sessions during a normal week); vigorous (participation in vigorous activities at least three times per week for at least 20 minutes per session); and inactive (students who do not register in other categories) ${ }^{4}$ This measurement was based on physical activity recommendations for adolescents by Sallis et al..$^{5}$ In the school survey, around 80 per cent of NSW children were reported to be sufficiently physically active (that is, in the adequate or vigorous activity groups) $)^{4}$

Television viewing may promote childhood obesity through two mechanisms: reduced physical activity; and increased dietary energy intake, either during viewing or as a result of food advertising. ${ }^{6}$ Observational studies have reported inconsistent associations between time spent watching television and prevalence of obesity. However, recent evidence from intervention trials suggests that reducing television viewing reduces the risk of obesity, and promotes weight loss in obese children. ${ }^{7}$ 


\section{FIGURE 14}

\section{TIME SPENT PLAYING COMPUTER GAMES OR WATCHING TELEVISION OR VIDEOS, CHILDREN AGED 5-12 YEARS, NSW, 2001}
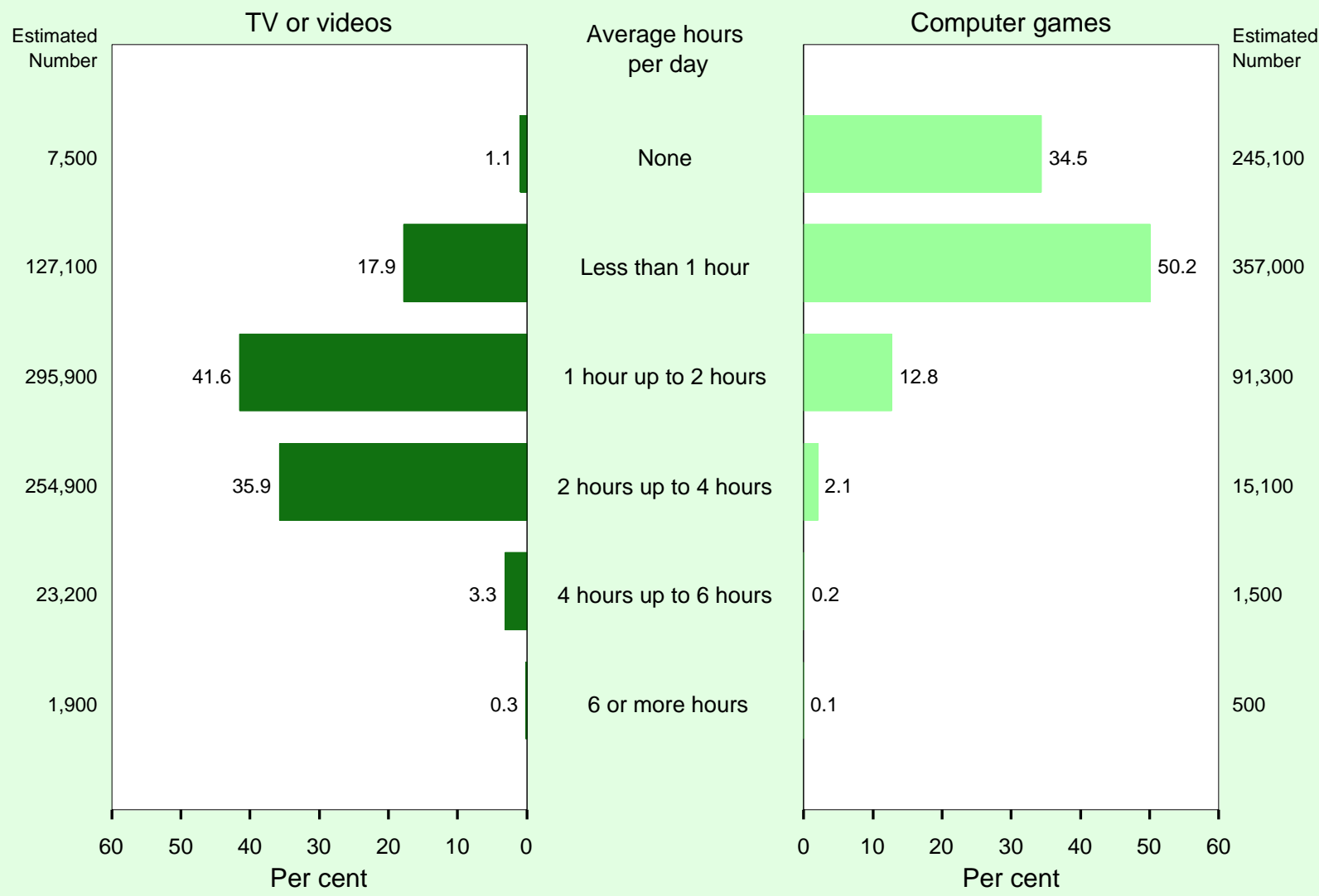

Note: Estimates based on 5888 respondents.

Source: New South Wales Child Health Survey 2001 (HOIST). Centre for Epidemiology and Research, NSW Department of Health.

It is not possible to accurately measure levels of physical activity among children in an interview survey such as the New South Wales Child Health Survey 2001, because parents or carers cannot accurately estimate the child's activity levels. Instead, parents and carers were asked about participation in sports and outdoor activities, and in organised physical activities outside school, as markers of activity levels. Additionally, respondents were asked whether they had actively discouraged their child from playing specific sports because of concerns for injury or safety. Parents or carers of children aged 5-12 years were also asked about the time their child spent watching television and playing computer games.

\section{Participation in sports and outdoor activities}

Overal, 91.9 per cent of children aged 5-12 years participated in sports and outdoor activities in the last 12 months (93.1 per cent for males and 90.6 per cent for females). The most frequently-reported sports and activities among males were: bike riding (67.9 per cent), soccer (56.0 per cent), swimming (41.6 per cent), cricket ( 22.8 per cent), rollerblading (23.0 per cent), tennis (15.5 per cent), rugby league (14.3 per cent), scootering (15.0 per cent), basketball (10.2 per cent), and Australian rules football (7.2 per cent). Only 4.5 per cent reported playing rugby union. The most frequently reported sports and activities among females were: bike riding ( 64.8 per cent), swimming ( 44.6 per cent), rollerblading (31.5 per cent), netball (28.9 per cent), scootering (16.8 per cent), soccer (16.3 per cent), and tennis (13.0 per cent) (Figure 13).

\section{Frequency of participation in organised physical activities outside school}

Overall, 58.1 per cent of children aged 5-12 years were reported to have 'participated in sports with a coach outside school hours' at least once per week in the past 12 months. Almost two-thirds of males (64.7 per cent) and half of females (51.5 per cent) were reported to participate at least once per week; while more than a third of males (38.9 per 
cent) and almost one-quarter of females (23.3 per cent) were reported to participate more than once per week.

Smaller proportions of children were reported to participate in 'other' organised physical activities, such as dance, gymnastics, or martial arts, outside school hours. Females (42.8 per cent) were more likely than males (19.0 per cent) to be reported to participate in these activities at least once per week.

\section{Injury and safety concerns about sports and outdoor activities}

In the New South Wales Child Health Survey 2001, 31.8 per cent of parents or carers of children aged 5-12 years reported discouraging children from playing sport (38.9 per cent for males and 24.2 per cent for females) because of concerns for injury and safety. Among males, the most frequently discouraged sport was rugby league (22.8 per cent), followed by rugby union (7.5 per cent) and Australian rules football (2.9 per cent). Among females, the most frequently discouraged sports and activities were roller-blading (2.6 per cent), rugby league ( 2.0 per cent), and soccer (2.0 per cent).

At least among males, the sports that were most discouraged by parents or carers were consistent with those most associated with sporting injuries. The sports causing the most injuries among NSW high school students in 1994-1995 were: rugby union, rugby league, gymnastics, netball, hockey, and Australian rules football. ${ }^{8}$

\section{Time spent watching television or videos and playing computer games}

Children of both sexes aged 5-12 years were most commonly reported to watch an average of between one and two hours of television or videos per day (41.3 per cent of males and 42.0 per cent of females). Around one in five children of both sexes (16.8 per cent of males and 19.0 per cent of females) were reported to watch an average of less than one hour per day. Just over one-third (37.6 per cent of males and 34.1 per cent of females) were reported to watch an average of between two and four hours per day, while a small minority (3.4 per cent of males and 3.8 per cent of females) were reported to watch four or more hours per day. Overall, 39.5 per cent of all children aged 5-12 years watched an average of two or more hours of television per day.

Although television and video watching was similar among males and females aged 5-12 years, males were reported to spend more time playing computer games. More than three-quarters of males (77.3 per cent) were reported to play computer games, compared with just over half of females (53.0 per cent). More than one in five males (21.9 per cent) were reported to play computer games for an average of more than one hour per day, while the comparable figure for females was less than one in $10(8.2$ per cent) (Figure 14).

\section{References}

1. French SA, Fulkerson JA, Story M. Increasing weight-bearing physical activity and calcium intake for bone mass growth in children and adolescents: A review of intervention trials. Prev Med 2000; 31: 722-731.

2. Sallis JF, Prochaska JJ, Taylor WC. A review of correlates of physical activity in children and adolescents. Med Sci Sports Exerc 2000; 32: 963-975.

3. Booth M, Macaskill P, McLellan L, et al. NSW Schools Fitness and Physical Activity Survey 1997. Sydney: NSW Department of School Education, 1997.

4. Booth ML, Okley AD, Chey T, Bauman AE, Macaskill P. Epidemiology of physical activity participation among New South Wales school students. Aust NZ J Public Health 2002; 26: $371-4$

5. Sallis, JF, Patrick K, Long BJ. Overview of the International Consensus Conference on Physical Activity Guidelines for Adolescents. Paediatric Exercise Science 1994; 6(4): 299-301.

6. Bar-On ME. The effects of television on child health: Implications and recommendations. Arch Dis Child 2000; 83: 289-292.

7. Robinson TN. Television viewing and childhood obesity. Pediatr Clin North Am 2001; 48: 1017-25.

8. Northern Sydney Area Health Service. New South Wales Sports Injury Report. Sydney: NSAHS, 1997. 